\title{
Developing Assessment Instrument to Measure Physics Problem Solving Skills for Mirror Topic
}

\author{
Arum Karima Permatasari ${ }^{1}$, Edi Istiyono ${ }^{2}$, Heru Kuswanto ${ }^{3}$
}

\begin{tabular}{l} 
ARTICLE INFO \\
\hline Article History: \\
Received 29.12 .2018 \\
Received in revised form \\
05.03.2019 \\
Accepted \\
Available online 01.07 .2019
\end{tabular}

\begin{abstract}
The Problem solving skills are needed to students in physics learning. Physic problem can be seen in daily, such as mirror topic. Student who has problem solving skills can solve question of mirror topic not only by equation, but also use concepts and principles what he know. This research aimed to develop a valid physics assessment to measure problem-solving skills for Senior High School Students grade XI. The development stages include: (1) determination for general purpose, (2) conceptual definition, (3) operational definition, (4) establishment for indicators, (5) construction for grid questions, and (6) determination for test form. The development stage includes: (1) the content validation by experts, (2) revision of the instrument, (3) the prepation for research (4) trial and empirical validation. The disseminate stage was publication of journal. Subjects of this research was 55 students of Senior High School 2 Yogyakarta. Students as subjects of this research was chosen who had learned mirror topic. According the result of the content validation and the empiric validation, assessment instrument was valid to measure physics problem solving skills in mirror topic. The content validation has 0,96 for all items, while the empirical validation has $0,97 \pm 0,18$ for Infit MNSQ, it means all items are in accordance with PCM model. the assessment instrument has value of goodness of fit un range -0.94 to 1.12 and has level of item difficulty in range $-0,94$ to 1.12 , those mean all items in the assessment instrumen are good. Futhermore, the assessment instrument is valid in the content validation and the empirical validation and able to measure physics problem solving skills. Categories problem-solving skills of subjects obtained of low, medium and high category.
\end{abstract}

C IJERE. All rights reserved

\section{Keywords:}

Assessment instrument, mirror topic, physics assessment, physics problem solving skills, reasoned multiple choice

\section{INTRODUCTION \pm}

Students need problem solving skills. In preparation for the challenges of the 21st century, students are required to have problem solving skills. Problem solving skills are needed so students can compete globally in this century (Dewi \& Prahani, 2017; McNeill, Gosper \& Xu, 2012). Physics learning contains problems of daily life, problem solving skills are very important in learning physics because students are not enough just to look at the quantitative aspects of solving these equations and the way mathematics is used, but also qualitative analysis to choose concepts and principles correctly in answering questions (Docktor, Strand, Mestre \& Ross, 2015). Students who have problem solving skills can solve physics problems by connecting knowledge, skills and understanding possessed by students, so that problems are solved. Student gain new knowledge after solving the problem (Gok, 2010; Hopson, Simms \& Knezek, 2001). The results of the solutions can be evaluated by the truth of the answers chosen by students (Helaiya, 2010). Problem solving skills are the main topic in physics education research, because it has benefits for the long term. Problem solving skills also help students to understand the concepts of physics in real conditions (Nadapdap \& Istiyono, 2016).

Problem solving skills are very important in physics learning. Core Competencies (KI) in physics apply procedural knowledge to solve problems, so teachers must assess students' problem solving skills and assessments are also used to determine competency achievement by students (Kemendikbud, 2016). It shows that important problem solving skills in physics learning and instrument needs assessment to assess problem solving skills. The assessments used by educators so far are only limited to the assessment of low level cognitive domains, while the high level cognitive domains to train high-level thinking processes of students (HOTS), such as HOTS Bloomian, Marzonian HOTS, Critical Thinking and Problem Solving (Heong, Othman, Yunos, Kiong, Hassan, \& Mohamad, 2011; McNeill, 2012; Istiyono, Mardapi \& Suparno, 2014) have not been developed. Teachers need assessment instruments that can really measure students' problem solving skills.

\footnotetext{
${ }^{1}$ Corresponding e-mail: arumkarima@gmail.com, https://orcid.org/0000-0002-9379-0480

${ }^{2}$ https://orcid.org/0000-0001-6034-142X

${ }^{3}$ https://orcid.org/0000-0002-2693-8078

Yogyakarta State University $1,2,3$
} 
Assessment is part of physics learning and determines success or failure of learning. Assessment according to students is seen in terms of cognitive, affective and psychomotic (Kerry \& David, 2011). In physics learning, students' cognitive abilities are very helpful in solving physics problems, such as the skills to support and understand the principles of physics correctly, skills to understand and understand physics problems effectively. Students having problem solving skills can easily solve physics problems with their physics concepts (Mundilarto, 2002). Making assessment instruments in this research to measure students' problem solving skills. Problem solving skills are very useful for physics because physics is often found in everyday life. Physics problem solving skills are a solution to physical problems based on what students already have, such as knowledge, understanding and skills.

Instruments for assessing problem solving skills is considered valid if the assessment instrument can measure students' physics problem solving skills. Instruments for assessing problem solving skills will produce accurate data on students' physics solving abilities. It means teacher needs a quality assessment tool (Asysyifa, Jumadi, Wilujeng \& Kuswanto, 2019). Instrument validation is needed, because instrument validation shows the accuracy of the assessment instrument function.

Uno (2007) argued that students who have problem solving skills will think by gathering facts and analyzing information found. Learning in 21st century is expected to understand the skills needed by students, both low-level and high-level thinking skills, to improve students' problem-solving skills in physics learning to be developed. McDonald (2010) also said that students have solving skills that can represent verbal representations and qualitative problems into non-mathematical representations, namely diagrammatic representations.

The research on physics problem solving skills has been done, they are evidenced by the development of indicators of problem solving skills by experts. Polya (1957) had developed the indicators and solving skills needed by students: 1) solving problems, 2) plan solutions, 3) implementing plan solutions, and 4) evaluating. Another opinion about indicators of students' problem solving skills developed by Haleiya (2010), namely: 1) identifying problems or problem solving processes; 2) define the problem that is the problem is different from what it should be, 3) alternative thinking from several solutions; 4) verify the solution; 5) verification process of a solution.

Wier (1974) said that physics problem solving skills are the skill to solve problems by defining problems, planning solutions, implementing planned solutions and evaluating the solutions that have been done. The problem identification stage is that students know the physics concept of the problem given and identify the data to be an interpretation of the problem. The planning stage of the solution is students plan strategies to solve physics problems given based on their knowledge (Polya, 1957). The stage of implementing plan solution is to try the solution that was planned in the previous stage. In this stage, students use equations, substitute known values into equations and perform mathematical operations to find solutions. Evaluation is needed to criticize the results of problem solving that have been chosen, so that problem solving skills can be used to answer the problem correctly, logically and completely and students who have problem solving skills can draw conclusions from steps taken from solving the problem correctly (Heller \& Heller, 2010).

Based on the opinions of experts, the aspects of physics problem solving abilities used in this study can be seen in Table 1.

Table 1. Indicators of Physics problem solving skills

\begin{tabular}{|c|c|c|}
\hline Aspect & Subaspect & Indicators of Physics problem solving skills \\
\hline $\begin{array}{l}\text { Identification of } \\
\text { Problem }\end{array}$ & Identificaty & $\begin{array}{c}\text { Identification of information is a problem of } \\
\text { physics }\end{array}$ \\
\hline Planing a Solution & Plan & Making a strategy to solution \\
\hline \multirow[t]{2}{*}{ Implementing a Solution } & Connect & Solve a problem by data \\
\hline & Apply & $\begin{array}{l}\text { Connect variables in completing multiple } \\
\text { representations }\end{array}$ \\
\hline Evaluation & Criticize & Critical to the results of the conclusion solution \\
\hline
\end{tabular}


The choice of multiple choice format is often used in physics assessment, eventhough rarely able to measure high-level thinking skills (Erfianti, Istiyono \& Kuswanto, 2019) include problem solving skills.. In fact, multiple choice has weaknesses, it is student answer questions (Delen, 2015) and cheating among students (Dindar, Yurdakul \& Donmez, 2013), so it cannot measure students' problem solving abilities. The use of reasoned multiple choice to reduce students who answer randomly. The use of multiple-reasoned selection can be seen by the reason students choose the answer. Instrument of physics problem solving skills with reasoned multiple choice format had been made and declared valid to measure students' physics problem solving skills according to the results of content and empirical validation.

Multiple choice which is often used in physics assessment. Multiple choice modification was made to adjust the physics assessment goals, one of which was reasoned multiple choice. Reasoned multiple choice provides questions and answers to the most appropriate questions and there are reasons students choose as reasons for choosing answers (Miller, 2008). The use of reasoned multiple choice is a multiple choice test that can measure abilities higher in education, such as problem solving skills (Kubiszyn \& Borich, 2013).

Reasoned multiple choice is different from multiple-choice formats that are often used in physics assessments. Multiple choice uses dichotomous items, value 1 for correct answer and value 0 for wrong answer. The use of dichotomus cannot be used to measure the ability to solve physics problems, because it does not consider the steps taken by students in solving problems (Nadapdap \& Istiyono, 2016). Guidelines for scoring instruments for assessing physics problem solving skills use four polytomus categories and criteria by adopting test assessment guidelines from Istiyono, Mardapi and Suparno (2014). Scoring guidelines and criteria can be seen in Table 2 .

Table 2. Guidelines for Assessment Instrumen of Physics Problem Solving Skills

\begin{tabular}{rcc}
\hline \multirow{2}{*}{ score } & \multicolumn{2}{c}{ Criteria } \\
\cline { 2 - 3 } & Answer & Reason \\
\hline 4 & Correct & Correct \\
\hline 3 & Wrong & Correct \\
\hline 2 & Correct & Wrong \\
\hline 1 & Wrong & Wrong \\
\hline
\end{tabular}

\section{METHOD}

The model of research is research and development, better known as $4 \mathrm{D}$ (4D model). The phase of the $4 \mathrm{D}$ model consists of the phases of defining, planning (design), developing, and developing (deployment) (Thiagarajan \& Semmel, 1974) which can be seen in Figure 1. Instruments that have been developed in accordance with aspects and sub-aspects of physics problem solving capabilities students in the mirror topic of class XI SMA. The subjects of this research were 55 students of Senior High School 2 Yogyakarta. Students as research subjects were selected using purposive sampling techniques, namely those who had studied the mirror topic. Question items from the instruments for assessing physics problem solving skills consist of 10 questions.

\section{Material}

The instrument used for collecting data consists of grids arranging question, two-tier multiplechoice, answer key and assessment rubrics, and instrument assessment validation sheets developed. The result of the test were analyzed by estimation result, goodness of fit, and item difficulty level.

\section{Data Analyse}

The data collected is validation data from the instrument for assessing students 'physics problem solving abilities and students' physics problem solving abilities. Validation data is derived from the results of content validation by experts. The content validation expert consisted of 2 Yogyakarta State High School 2 physics teachers and 2 lecturers from Magister of Physics Education of Yogyakarta State University. The content validation was analyzed using V's Aiken (1985) equation which can be seen in equation (1):

$$
V=\frac{\Sigma s}{(n(c-1))}
$$


Information:

$s=\mathrm{R}-\mathrm{lo}$

$l o=$ the lowest rating number of validity $(l o=1)$

$c=$ The highest rating number of validity $(c=3)$

$R=$ the number that giving by validator

The scale used in the validation sheet is a Likert scale with four scale category. Under the Right-Tail table of probabilities (P) for Selected Value of Validity Coefficient (V) "that on a scale of four categories with 4 validator, the instrument said to be valid if the coefficient $V=0.92$ (Aiken, 1985). Furthermore, the students answers' were analized by QUEST Program. It also can analized problem solving skills of students.

Physics problem solving skills of students were obtained from the calculation of scores from assessment instruments with rating guidelines in Table 2. The ability to solve students' physics problems is analyzed using SPSS to calculate the mean, and standard deviation, then the students' physics problem solving categories can be divided based on Table 3 .

Table 3. Interval Scores and Physics problem solving skills Category

\begin{tabular}{cc}
\hline interval Scores & Category \\
\hline$X>$ Mean \pm SD & High \\
\hline Mean - SD $\leq x \leq$ Mean \pm SD & Medium \\
\hline$X<$ Mean - SD & Low \\
\hline
\end{tabular}

\section{Findings}

Validation is done to obtain validity information on the assessment instrument. Validation consists of content validation and empirical validation. Validation carried out by experts includes content validation, construction validation, discussion validation and display validation. Experts also provide suggestions for instrument improvements. The results of content validation in the instrument for assessing problem solving can be seen in Table 4.

Table 4. The Results of The Content Validity

\begin{tabular}{ccc}
\hline Question & V Aiken & Criteria of Question \\
\hline 1 & 0,96 & Valid \\
2 & 0,96 & Valid \\
3 & 0,96 & Valid \\
4 & 0,96 & Valid \\
5 & 0,96 & Valid \\
6 & 0,96 & Valid \\
7 & 0,96 & Valid \\
8 & 0,96 & Valid \\
9 & 0,96 & Valid \\
10 & 0,96 & Valid \\
Mean & 0,96 & Valid \\
\hline
\end{tabular}

Validation data were analyzed by equation (1), then the results of the analysis are described in Table 6 . Assessment instrument for physics problem solving skills obtained a V Aiken value of 0.96 for all questions and valid for measuring physics problem solving abilities for the mirror topic. The Empirical validation was done after content validation. Empirical validation was conducted by 55 students of Yogyakarta State High School 2 in class XI. Results can be seen in Table 5. 
Table 5. The results of empirical validation

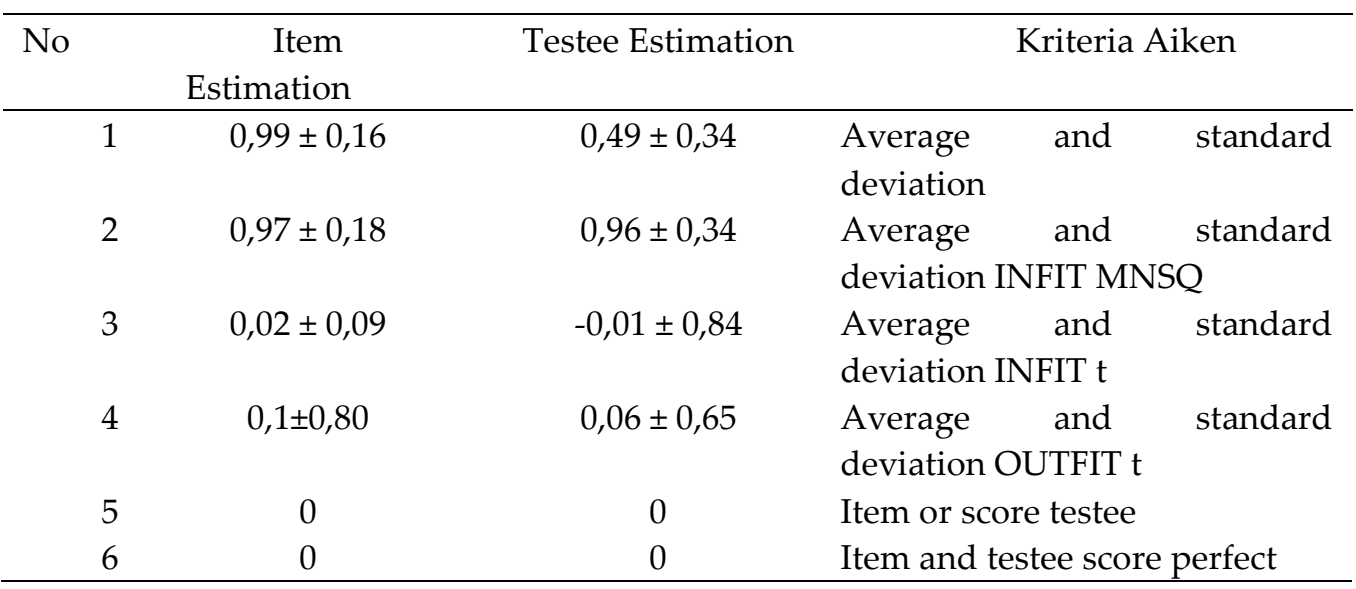

Goodness of fit is done to test the whole question of the instrument for assessing students' physics problem solving abilities. Goodness of fit was developed by Adam and Khoo (1996) by looking at INFIT Mean of Square and standard deviation or referring to INFT $t$ average (Mean INFIT $t$ ) and standard deviation. The item matches the model if the MNSQ INFI value ranges from 0.77 to 1.30 and uses INFIT $t$ from -2.0 to 2.0.

Based on Table 5 , the instruments for assessing the ability to solve physical problems have MNSQ INFIT values of $0.97 \pm 0.18$ and $0.96 \pm 0.34$. This shows that all items are in accordance with the model. In addition, INFIT $t$ assessment instruments are $0.02 \pm 0.09$ and $-0.01 \pm 0.84$. The item acceptance limit uses MNSQ infit between 0.77 to 1.30 . The results of the study indicate that the value of goodness of fit of all items is between two boundary lines, namely 0.77-1.30.

items of the assessment instrument developed in accordance with the Partial Credit Model (PCM) model and valid based on empirical tests with the distribution of Goodness of Fit based on INFIT MNSQ all valuation instrument items are in the range of 0.77-1.30 (see Table 6). This means all items of the assessment instrument are in accordance with the PCM model.

Table 6. Value of MNSQ INFIT each items.

\begin{tabular}{|c|c|c|}
\hline Item & \multicolumn{2}{|c|}{ MNSQ INFIT } \\
\hline Item 1 & $0.77-1.00$ & $1.00-1.30$ \\
\hline Item 1 & & $\sqrt{ }$ \\
\hline Item 2 & $\sqrt{ }$ & \\
\hline Item 3 & $\sqrt{ }$ & \\
\hline Item 4 & $\sqrt{ }$ & $\sqrt{ }$ \\
\hline Item 5 & & $\sqrt{ }$ \\
\hline Item 6 & & $\sqrt{ }$ \\
\hline Item 7 & & $\sqrt{ }$ \\
\hline Item 8 & & \\
\hline Item 9 & $\sqrt{ }$ & \\
\hline Item 10 & $\sqrt{ }$ & \\
\hline
\end{tabular}

The level of difficulty per item can be seen from the value of difficulty items. The item is said to be good if the difficulty index is more than -2.0 or less than 2.0. This refers to the theory developed by Hambleton \& Swaminathan (1985). Based on the calculation of the magnitude of the difficulty level all items of assessment instruments can be seen in Table 7 .

Table 7. Level of Item Difficulty

\begin{tabular}{|c|c|c|c|}
\hline No & Level of Item Difficulty & No & Level of Item Difficulty \\
\hline 1 & $-0,94$ & 6 & $-0,72$ \\
\hline 2 & $-0,56$ & 7 & 1,12 \\
\hline 3 & 0,96 & 8 & $-0,75$ \\
\hline 4 & 0,88 & 9 & $-0,22$ \\
\hline 5 & 1,06 & 10 & $-0,52$ \\
\hline
\end{tabular}


Based on Table 7, it can be known that the highest level of problem difficulty is 1.12 in question 7, while the lowest level of difficulty is -0.94 in question 1 . The results of students' physics problem solving skills were obtained from the results of test analysis. The following are the results of test analysis using SPSS in the form of a statistical test description that can be seen in Table 8 .

Tabel 8. Descriptive Statistic for The Results of test

\begin{tabular}{llllll}
\hline & N & Min & Max & Mean & SD \\
\hline Value & 55 & 14 & 36 & 29,29 & 4,1 \\
Valid N & 55 & & & & \\
\hline
\end{tabular}

Based on Table 8, it shows the minimum and maximum scores. From the results, the minimum score is 14 and the maximum score is 36 , with a standard deviation of 4.1. In addition, the average score produced by 32 students is 29.29. Students' problem solving skills can be analyzed using the SPSS distribution test. Based on the results of SPSS, obtained an average of 29 and a standard deviation of 4.1. Table 9 shows the intervals and categories of student physics problem solving skills.

Tabel 9. Category of Physics Problem Solving Skills of Students

\begin{tabular}{clc}
\hline $\begin{array}{c}\text { Interval } \\
\text { Score }\end{array}$ & Category & $\begin{array}{c}\text { Number of } \\
\text { Students }\end{array}$ \\
\hline$X>33$ & High & 11 \\
$24 \leq X \leq 33$ & Medium & 37 \\
$X<24$ & Low & 7 \\
\hline
\end{tabular}

Indicators that used in the research is problem solving skills developed by Polya (1971) which include: identifying of the problem, planning solutions, implementing of the plan, and evaluation. For details of students' problem solving skills can be seen in Table 1. Problem solving skills were analyzed from scores obtained from student test results (Docktor, et al., 2015; Nadapdap \& Istiyono, 2016). Furthermore, SPSS was analyzed to test normality and categorized according to Table 9.

Evaluation was conducted to assess problem solving skills to solve problems with results, 11 students had high criteria problem solving skills. It shows that students already have a high level of problem solving skills in the mirror topic. High problem solving skills from students show that students have physics problem solving skills, starting from identifying problems, planning solutions, implementing and evaluating solutions. Identifiying problems, namely students have been able to identify information from physical problems, in this case the problem of physics, then the information is interpreted in terms of physical concepts (Nadapdap \& Istiyono, 2016; Heller \& Heller, 2012). Next is planning solution, namely students have been able to make various possible strategies to solve physics problems, in this case is a matter of physics (Nadapdap \& Istiyono, 2016; Heller \& Heller, 2012). Implementing include links and implementing solutions. Connected aspects, have criteria that students have been able to connect problems in solving problems based on data. Aspects apply, students have been able to connect physical variables in solving physics problems in multi-representation (Nadapdap \& Istiyono, 2016; Heller \& Heller, 2012). The last aspect is the evaluation, in this case students have been able to examine the results obtained by the solution, then made whether the solution to the problem solving has been done right or wrong (Nadapdap \& Istiyono, 2016; Heller \& Heller, 2012). A high category of problem solving skills also shows that students have been able to apply the knowledge they have in the problems they have just encountered and show that students have achieved high level thinking skills.

\section{Result, Disscussion and Suggestion}

Assessment instrumen of physics problem solving skills used reasoned multiple choice for the form test. A question can be seen in Table 11 and an example of scoring guidelines from question can be seen in Table 12. The consideration for choosing a reasoned multiple choice format is knowing why students choose answers from questions and assessing physics problem solving skills based on selection of reasons (Nadapdap \& Istiyono, 2016; Istiyono, Mardapi \& Suparno, 2014; Miller, 2008; Kuviszyn \& Borich, 2013). The 
distribution of aspects and sub-aspects of the mirror topic on assessment instrument for physics problem solving skills can be seen in Table 10. Table 11 shows format test that used in the research.

Table 10. The Distribution of aspect and sup-aspect of Assessment Instrument for Physics Problem Solving Skills

\begin{tabular}{|c|c|c|c|c|}
\hline \multirow{3}{*}{ Aspect } & \multirow[t]{3}{*}{ Subaspect } & \multicolumn{3}{|c|}{ Capture } \\
\hline & & \multicolumn{3}{|c|}{ Mirror } \\
\hline & & Plan & Concave & Convex \\
\hline $\begin{array}{l}\text { Identification } \\
\text { of Problem }\end{array}$ & Identificaty & $\sqrt{ }$ & $\sqrt{ }$ & \\
\hline $\begin{array}{l}\text { Planing a } \\
\text { Solution }\end{array}$ & Plan & & $\sqrt{ }$ & $\sqrt{ }$ \\
\hline Implementing & Connect & & $\sqrt{ }$ & $\sqrt{ }$ \\
\hline a Solution & Apply & & $\sqrt{ }$ & $\sqrt{ }$ \\
\hline Evaluation & Criticize & & $\sqrt{ }$ & $\sqrt{ }$ \\
\hline
\end{tabular}

Table 11. Format test that used in the research.

\section{Question :}

An object is located $30 \mathrm{~cm}$ in front of a concave mirror and produce shadow at a distance of $60 \mathrm{~cm}$ in front of a concave mirror, if the object is shifted as far as $10 \mathrm{~cm}$, then the nature of the shadow is happening are ....
A. Real, inverted, and minimized
B. Real, inverted, and maximized
C. Real, inverted, and an equally large
D. Pseudo, upright, and maximized
E. Pseudo, upright, and minimized

\section{Reason :}

A. the more the object is placed and away from the focal point of the concave mirror, the shadow formed is pseudo, upright, and maximized

B. getting away from the focus point and approaching the center of the mirror's curvature, the image formed is real, inverted, and maximized

C. when an object is in the center of the curvature of the mirror, the image formed is real, inverted, and equally large

D. the more objects away from the center of the mirror curvature, the shadows that are formed are pseudo, upright, and maximized

E. when objects are placed in the mirror's focal point, the image that occurs is pseudo, upright, and minimized

Based on Table 12, we can see that students who can answer true for the reason, they get higher score than student who answer true for the question but the reason is wrong. It means students who can answer the reason correctly have physics problem solving skills dan understand the bacis concet correctly. 
Table 12. An Example Guideline Scoring

\begin{tabular}{|l|c|}
\hline \multicolumn{1}{|c|}{ Completion } & Score \\
\hline $\begin{array}{l}\text { An object is located } 30 \mathrm{~cm} \text { in front of a concave mirror and produce shadow at a } \\
\text { distance of } 60 \mathrm{~cm} \text { in front of a concave mirror, if the object is shifted as far as } 10 \mathrm{~cm}, \\
\text { then the nature of the shadow is happening is real, inverted, and an equally large } \\
\text { Reason: When objects are in the center of curvature of mirror, the image formed is } \\
\text { real, inverted and the equally great. } \\
\text { Answer: C } \\
\text { Reason: C }\end{array}$ & \\
\hline $\begin{array}{l}\text { Answer: A,B,D, oer E } \\
\text { Reason: C }\end{array}$ & \\
\hline $\begin{array}{l}\text { Answer: C } \\
\text { Reason: A,B,D or E }\end{array}$ & 3 \\
\hline $\begin{array}{l}\text { Answer: A,B,D or E } \\
\text { Reason: A,B,D or E }\end{array}$ & 2 \\
\hline
\end{tabular}

The assessment instrument was developed by aspects and sub-aspects of problem solving skills in the mirror topic. The assessment instrument uses a reasoned multiple choice test form. The results of validation of the assessment instrumen are 0,96 , thus the assessment instrumen is valid by content validation. The quality of the items in the IRT is determined by the suitability of the items with the Rasch model and item difficulty index. The results of the study show that the goodness of fit value of all items is between two boundary lines, namely $0.77-1.21$. The assessment instrumen has level of item difficulty is more than -2.0 or less than 2.0, thus the assessment instrument is good because has the level of item difficulty between them, namely in the range -0.94 to 1,12 . The assessment instruments developed have been declared valid in terms of content validation and empirical validation, so that the assessment instruments developed are valid for measuring students' problem solving skills.

Based on the results of students' problem solving skills that were successfully measured by the assessment instruments developed, students had a category of high problem solving skills, medium categories and low categories. The percentage of problem solving skills that have a high category is 11 students. 37 students have a medium category for problem solving skills and 7 students have a low category for problem solving skills. The research is limited to the mirror and the sample be used of the research is a few because limited by time and expense. Future research can develop assessment instruments with more topics, number of questions and the number of sample for assessment instruments for problem solving skills.

\section{REFERENCES}

Aiken, L. R. (1980). Three coefficient of analyzing of the realibility and validity of ratings. International of Educational and Phsycological Measurement, 45(1), 955-967.

Asysyifa,D.S., Jumadi, Wilujeng,I. \& Kuswanto,H. (2019). Analysis of students critical thinking skills using partial credit models $(\mathrm{Pcm})$ in physics learning. International Journal of Educational Research Review,4(2), 245-253.

Delen, E. (2015). Enhancing a computer-based testing environment with optimum item response time. Eurasia Journal of Mathematics, Science and Technology Education, 11(6), 1457-1472.

Dewi, I.N., Poedjiastoeti, S. \& Prahani, B.K. (2017). ELSII learning model based local wisdom to improve student' problem-solving skills and scientific communication. International Journal of Education and Research, 5 (1), 107-118.

Docktor, J. L., Strand, N. E., Mestre, J. P., \& Ross, B. H. (2015). Conceptual problem solving in high school physics. Physical Review Special Topics - Physics Education Research, 11(2). 
Dindar, M., Yurdakul, I. K., \& Dönmez, F. I. (2013). Multimedia in test items: Animated questions vs. static graphics questions. Procedia - Social and Behavioral Sciences, 106, 1876-1882.

Erfianti,L., Istiyono,E. \& Kuswanto,H. (2019). Developing lup instrument test to measure higher order thinking skills (Hots) Bloomian for senior high school students. International Journal of Educational Research Review,4(3),320-329.

Gok, T. (2010). The General assessment of problem solving processes and metacognition in physics educatin. Eurasia Journal of Physics and Chemistry Education, 2(2), 110-122.

Helaiya, S. (2010). Development and Implementation of Life Skills Programme for Student Teachers. Vadodara: Maharaja Sayaji Rao University of Baroda.

Heller, K., \& Heller, P. (2012). Cooperative problem solving in physics a user's manual. Universitas of Minnesota.

Heong, Y. M., Othman, W. B., Yunos, J. B., Kiong, T. T., Hassan, R. B., Mohaffyza, M., \& Mohamad, B. (2011). The level of marzano higher order thinking skills among technical education student. International Journal of Social Science and Humanity, 1(2), 121-125.

Hopson, M. H., Simms, R. L., \& Knezek, G. A. (2001). Using a technology-enriched environment to improve higher-order thinking skills. Journal of Research on Technology in Education, 34(2), 109-119.

Istiyono, E., Mardapi, D., \& Suparno. (2014). Pengembangan Tes Kemampuan Berpikir Tingkat Tinggi Fisika (PysTHOTS) Peserta Didik SMA. Jurnal Penelitian Dan Evaluasi Pendidikan, 18(1), 1-12.

Kemendikbud (2016). Permendikbud Nomor 24 Tahun 2016 tentang Standar Kompetensi Inti dan Kompetensi Dasar.. Jakarta: Kementerian Pendidikan dan Kebudayaan.

Kerry, E., \& David, G,. (2011). An-other look at assessment: Assessment in learning. New Zaeland Journal of Teacher Work, 8(1), 11-20.

Kubiszyn, T., \& Borich, G. D. (2013). Educational testing and measurement: Classroom Application sand practice. Hoboken, NJ: Willey.

Mcdonald, F. (2010). An inverstigation of student' problem solving skills in an introductory physics class (Doctoral Dissertation, University of Central Florida Orlando, Florida.

McNeill, M., Gosper, M., \& Xu, J. (2012). Assessment choices to target higher order learning outcomes: The power of academic empowerment. Research in Learning Technology, 20(3), 283-296.

Miller, P. W. (2008) Measurement and teaching. Indiana: Patrick W. Miller \& Associates.

Mundilarto. (2002). Kapita Selekta Pendidikan Fisika. Yogyakarta: Jurusan Pendidikan Fisika UNY.

Nadapdap, A. T. Y., \& Istiyono, E. (2017). Developing physics problem-solving skill test for grade X student of senior high school. Research and Evaluation in Education, 3(2), 114.

Polya, G. (1957). How to solve it: A new aspect of mathematical method. Doubloday Garden City.

Uno, H, B. (2007). Model Pembelajaran Menciptakan Proses Belajar Mengajar yang Kreatif dan Efektif. Jakarta: Bumi Aksara.

Weir, J. (1974). Problem solving in everybody's problem. The Science Teacher, 4, 16-18. 